old people screened. This attitude may be mistaken: old people in residential and nursing homes may still have unmet need. ${ }^{6}$

Some health workers were enthusiastic about the checks. They felt they were a valuable new method of discovering unmet need and were popular with patients. Others had a positive attitude but felt the changes required by the new contract were a great burden and so had not been able to organise checks on old people effectively in their first year.

In most practices the nurse was involved in organising and carrying out the checks but the amount of protected time allowed for doing them varied. The previous training of the nurses often included experience with old people but not their assessment in the community. This may reflect a lack of suitably trained nurses, the expense of employing them, or the amount of training available locally. The study was small and it was not surprising that we were not able to show any effect of nurse training on the results of the checks. However, functional assessment is a task which requires particular skills and assessors need to know what resources are available if they are to make best use of the results of the assessment. We were concerned that over a third of the practice nurses doing checks had had no training in assessment of old people at all.

Where checks were being offered, patients always had the option of being assessed at home, though some practices still did most checks in the surgery. This used less of the doctors' and nurses' time but may have detracted from the value of the procedure. It is unclear why more new problems were found when checks were done mainly, but not exclusively, at the patient's home. It may be that these practices selected high risk patients for further assessment in their homes.

\section{MEETING UNMET NEED}

The commonest referrals were for chiropody and occupational therapy; $5 \%$ of the old people assessed in the sample month needed a new referral for chiropody and $5 \%$ for occupational therapy. Locally these services have long waiting lists. The increased demand for these services needs to be matched by an increase in resources. The higher number of problems found in inner city areas probably reflects greater unmet need in deprived areas. This also needs to be addressed by appropriate allocation of resources.

In total, $43 \%$ of patients assessed had a new problem that needed action. This pick up rate seems to bo substantial though the actions taken suggest that mos unmet need can be handled at a primary care level: Only 3\% of new problems required referral to hospitak The present study was unable to find out the proportio of problems that were insoluble or trivial since the would have required asking practices to record infor mation in a suitable form. This would have change the way they carried out the checks. However, the finding that no problems were recorded for nearly half the old people in the sample is enough to suggest that the obligation to assess all old people annually needs to be questioned. For some patients, less frequem assessments may be sufficient after an initial check Also, the number of new problems found per patient; may diminish over the next few years if the checks are successful in helping to meet previously unmet neefs For these reasons, it is essential that the effectiveness of the checks on old patients is carefully monitored.

We thank the 20 practices that took part in the study and Sue Read for her help with data analysis.

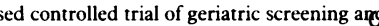
surveillance in general practice. $\mathcal{F} R$ Coll Gen Pract 1979;29:733-42.

2 Vetter NJ, Jones DA, Victor CR. Effect of health visitors working with elde patients in general practice: a randomised controlled trial. BMF 1984;28 369-72.

3 Wormald RPL, Wright LA, Courtney P, Beaumont B, Haines AP. Visu problems in the elderly population and implications for services. $B M$ 1992;304:1226-9.

4 Clark CM. Mandatory assessment of patients aged over 75. BMF 1991:303.5

5 Varnam M. Brewin L Oliver P, Barker M, Polnay J. Basu P, 2 al. In practice collaboration for functional assessment in the elderly. $B M \mathcal{F} 199^{\circ}$. 303:649-50.

6 Hepple J, Bowler I, Bowman C. A survey of private nursing home residents Weston Super Mare. Age Ageing 1989;18:61-3.

(Accepted 2 fuly 1992)

\title{
Assessment of patients aged over 75 in general practice
}

\author{
Jill Tremellen
}

\begin{abstract}
Objectives-To evaluate the assessment scheme for people aged 75, to establish doctors' and nurses' views on the value of the assessment scheme, and to seek patients' opinions on elderly assessments.

Design-Data on the assessment process were collected from individual practices. Questionnaires were sent to doctors and practice nurses undertaking assessments and to a sample of elderly patients.

Subjects -31565 patients aged 75 and over and all doctors registered with Wiltshire Family Health Services Authority, as well as practice nurses assessing elderly patients. A $2 \%$ random sample of elderly patients was selected to answer questions on patient satisfaction.
\end{abstract}

Main outcome measures-Numbers of patients accepting the invitation for assessment, who carried out the assessments and where, what unmet needs were identified, and by whom.

Results -20192 patients $(64 \%)$ accepted the assessment offer. Doctors carried out 8786 assessments and nurses 10779 . Although $12317(61 \%)$ were carried out in the home, nurses did most domiciliary assessments $(7122 / 11883)$. Nurses with extra quali- fications identified the highest number of unme needs (400/1000 visits). 155 of $228(68 \%)$ doctors thought assessments unnecessary whereas 25 of 48 (52\%) of nurses thought them important. 93\% patients found assessment useful.

Conclusions-Doctors see no merit in the scheme. most undertake assessments opportunistically and pick up few new problems. Nurses who see it as important require further training to fit them to $\phi_{G}$ home visits confidently. Patients who were assessed found it worth while. The case for developing specialist community nurse for elderly people shoug be investigated.

\section{Introduction}

The 1990 general practitioner contract requirê general practitioners to offer all patients aged 75 and over an annual home visit and assessment. The areas of assessment are specific: general function, to incluof continence, mobility, and mental state; sensory assese. ment; social assessment; and review of treatment.

This study was undertaken to measure the uptake of invitations for assessment; to examine who carried out 
the assessments, and where; and to document the needs identified and subsequent referrals. In addition the views of doctors, nurses, and elderly people on assessment were investigated.

\section{Subjects and methods}

Wiltshire Family Health Services Authority data show that on 1 April 1990, 39516 patients aged 75 or over were registered with 281 family doctors based in 83 practices. I collected data from 77 practices, 73 of which $(88 \%)$ provided complete information.

\section{IMPLEMENTATION OF THE ASSESSMENT SCHEME}

Data were collected by the practices on prepared sheets which showed how many patients had been offered an assessment, how many had accepted, and who had undertaken the assessment and where. A separate sheet recorded referral numbers and the agency of referral. These sheets together with standard patient assessment cards were given personally to every practice in April and March. The sheets were simple to complete and acted as a means of collecting information that the practice themselves required. Each practice was visited quarterly to collate information from the sheets. The only validation in the study was by regular checking with professionals responsible for carrying out assessments and collating practice data.

\section{VIEWS OF FAMILY DOCTORS AND PRACTICE NURSES}

Questionnaires were sent to every general practitioner (281) and to practice nurses (54) conducting assessments. Questionnaires were sent through the practice managers with a covering letter; the letters were followed up in most cases by a telephone call. There was an $83 \%$ (232) response rate from doctors and $89 \%$ (48) response rate from nurses.

\section{VIEWS OF PATIENTS}

A small sample of $360(2 \%)$ elderly patients was selected from six practices, two from each of the three health districts in the family health services authority.

TABLE I - Uptake of assessments by elderly patients according to practice organisation

\begin{tabular}{lcccc}
\hline Staff assessing patients & $\begin{array}{c}\text { No of } \\
\text { practices }\end{array}$ & $\begin{array}{c}\text { No of patients } \\
\text { invited }\end{array}$ & $\begin{array}{c}\text { No of } \\
\text { acceptances }\end{array}$ & $\begin{array}{c}\text { Acceptance } \\
\text { rate (\%) }\end{array}$ \\
\hline General practitioner $100 \%$ & 13 & 4663 & 3359 & 72 \\
General practitioner $>80-99 \%$ & 5 & 3022 & 2478 & 82 \\
General practitioner and practice nurse & 28 & 10612 & 6557 & 62 \\
Practice nurse $>80-99 \%$ & 14 & 6003 & 3260 & 54 \\
Practice nurse $100 \%$ & 13 & 7663 & 4538 & 59 \\
\hline Total & 73 & 31963 & 20192 & 63 \\
\hline
\end{tabular}

TABLE II -Numbers of home assessments conducted by professional group

\begin{tabular}{lccc}
\hline & $\begin{array}{c}\text { Total No of } \\
\text { assessments }\end{array}$ & $\begin{array}{c}\text { No of home } \\
\text { assessments }\end{array}$ & $\begin{array}{c}\text { Proportion of home } \\
\text { assessments (\%) }\end{array}$ \\
\hline General practitioners & 8786 & 4761 & 54 \\
Practice nurses & 5754 & 2850 & 50 \\
Practice nurses with specialist qualifications ${ }^{\star}$ & 5025 & 4272 & 85 \\
\hline Total & 19565 & 11883 & 61
\end{tabular}

^Including 379 home assessments by district nurses and health visitors attached to practices.

TABLE III - Number of referrals according to practice organisation

\begin{tabular}{lccc}
\hline Practice staff assessing patients & $\begin{array}{c}\text { No of } \\
\text { practices }\end{array}$ & $\begin{array}{c}\text { Total No of } \\
\text { referrals }\end{array}$ & $\begin{array}{c}\text { No of referrals/ } \\
100 \text { assessments }\end{array}$ \\
\hline General practitioner $100 \%$ & 13 & 164 & 5 \\
General practitioner $>80-99 \%$ & 5 & 28 & 1 \\
General practitioner and practice nurse $\sim 50 \%$ & 28 & 639 & 11 \\
Practice nurse $>80-99 \%$ & 14 & 1721 & 38 \\
Practice nurse $100 \%$ & 13 & 3264 & 74 \\
\hline Total & 73 & 1858 & 57 \\
\hline Practice nurses with qualifications & 16 & & \\
\hline
\end{tabular}

TABLE IV-Referrals of elderly patients to different services after assessment

\begin{tabular}{lc}
\hline Sector & No of referrals \\
\hline Health services & 1454 \\
General practitioner & 549 \\
Social services & 752 \\
Voluntary services & 236 \\
Other & 273 \\
\hline Total & 3264 \\
\hline
\end{tabular}

Practice staff selected 30 patients who had refused and 30 who had accepted the invitation. Questionnaires were sent to patients from the family health services authority and returned to the practice, from where they were collected. The questionnaire was returned by 156 of $180(87 \%)$ patients who accepted assessment and by 103 of $180(57 \%)$ who refused it.

\section{ANALYSIS OF RESULTS}

The results of questionnaires were coded and entered into a computer for analysis with the statistical package SPSS. Practices were divided into five groups for analysis: those in which general practitioners did all assessments, general practitioners did over $80 \%$, general practitioners and practice nurses did similar proportions, practice nurses did over $80 \%$, and practice nurses did all. Nurses with specialist qualifications (health visitor, district nurse, English National Board 941 care of the elderly certificate) were also analysed separately.

\section{Results}

The 73 practices which supplied full data sets had offered assessment to 31963 patients aged over 75 . A total of $20192(63 \%)$ accepted the offer and of these, 19565 (97\%) had been assessed by April 1991. Practices reported that many patients did not reply to the invitation rather than refusing outright.

The way practices managed the assessment scheme varied widely (table I). In some virtually all assessments were carried out by general practitioners while in others all were done by practice nurses. The highest uptake of invitations was among the 18 practices in which general practitioners did most assessments (76\%). In the 27 practices where practice nurses did all or most of the assessments uptake was $57 \%$. Doctors carried out the lowest proportion of assessments in patients' homes, while practice nurses with specialist qualifications did $85 \%$ of their assessments in the home (table II).

Substantial differences in referral patterns by professional background and training were also found. In all 3264 referrals resulted from the 19565 assessments, an overall rate of $167 / 1000$. However, the referral rate from practice nurses with specialist qualifications was over twice this: $400 / 1000$ visits. Analysis by practice organisation of assessments showed that the referral rate was lowest in practices in which $80-100 \%$ of assessments were carried out by general practitioners and highest in practices in which all assessments were done by practice nurses (table III).

Table IV shows where patients were referred after assessment. Referrals to health services were most common, most of these were for hearing $(29 \%$ of referrals to health services and $18 \%$ of all referrals) or to chiropody services $30 \%$ of health service referrals and $18 \%$ of all referrals).

\section{ATTITUDES TOWARDS ASSESSMENTS}

Attitudes of general practitioners and practice nurses to the assessment differed greatly. Table $\mathrm{V}$ shows two thirds of general practitioners regarded assessments as unnecessary, usually because they 


\begin{tabular}{lccccc}
\hline & \multicolumn{4}{c}{ No (\%) responding } & \multirow{2}{*}{ Total } \\
\cline { 2 - 5 } & Unnecessary & Necessary & Important & Vital & (15) \\
\hline General practitioners & $155(68)$ & $57(25)$ & $1(0.4)$ & 228 \\
Practice nurses & $3(6)$ & $20(42)$ & $21(44)$ & $4(8)$ & 48 \\
\hline
\end{tabular}

considered their patients were already well known to them. By contrast over half the nurses rated assessments as important or vital, a view held by only $16(7 \%)$ general practitioners. Differences in attitudes to health promotion were also substantial: $43(90 \%)$ nurses compared with $132(58 \%)$ general practitioners said they saw health promotion as a key part of the assessment.

Only four respondents who had been assessed did not find the assessment helpful. Of those who welcomed the assessment, three quarters said this because it was good to know the doctor or nurse cared. Not surprisingly, the response rate from those who had refused the assessment was low. Those who responded largely comprised those who reported that their health was as good as they could expect for their age (38 patients) and those who visited the doctor regularly anyway (38 patients). The remainder gave other reasons for refusing an assessment.

\section{Discussion}

Since 1964, when Williamson first identified the extent of unreported disease among elderly people, there has been considerable discussion concerning the appropriateness, benefits, and logistics of anticipatory care. ${ }^{1}$ During the past 30 years the focus of preventive care has shifted from uncovering disease to detecting unreported or poorly reported conditions. This approach has now widened to include functional, social, and environmental factors affecting the health of elderly people. ${ }^{2}$ One of the main influences on the development of case finding programmes has been the assumption that elderly people underconsult. Severa studies have found that although elderly people undoubtedly have greater morbidity, ${ }^{3}$ they consult their doctor more frequently than younger adults. Indeed, those that do not consult regularly have been found to be healthy. ${ }^{56}$ However, elderly people and their relatives still tend to accept many minor symptoms as being a natural part of aging.

\section{VALUE OF SCREENING}

Substantial evidence exists to show that case finding assessment uncovers unreported needs, ${ }^{7-11}$ but it is difficult to measure the effect of such a programme on the health of elderly people. Most studies so far have used the traditional measures of mortality and morbidity-incidence of hospital admissions and length of hospital stay. ${ }^{711} \mathrm{~A}$ randomised controlled trial in Newcastle recently showed that a screening programme had significantly improved the morale of elderly people but had not reduced physical problems, or increased ability to carry out activities of daily living. ${ }^{12}$ I also found evidence to support the view that patients value somebody caring about them. Illife et al showed that an annual assessment would uncover new cases of depression and dementia. In their study one in five elderly people (22\%) had evidence of depression; nevertheless, new information leading to effective medical and social intervention was limited. ${ }^{13}$ The noncomparability of these studies make it difficult to draw any firm conclusion.

In Wiltshire the overall uptake of assessment $(64 \%)$ was considerably lower than the $75 \%$ predicted. ${ }^{14}$ This relatively low acceptance rate clearly limits the usefulness of the data for population based health care

planning. Although those who were assessed welcomed it, blanket screening of elderly people annually may be both crude in structure and expensive in time and resources. Sophisticated measures have been devised over the past decade to identify those elderly people most at risk ${ }^{815}$ and a more efficient form of surveillance could concentrate effectively on vulnerable elderly people.

\section{OPPORTUNISTIC SCREENING}

Although $76 \%$ of patients accepted general practitioners' invitations for assessment, almost half were done in the surgery rather than in the house, as Wallace had recommended. The value of social and environmental assessments done in the surgery is doubtful.

Most doctors considered that assessment was unnecessary as their patients were already well known to them. The low level of referrals from doctors for social care suggests either that doctors do indeed know all their patients and that their functional as well as their clinical needs are being met, or that the social and functional assessment is only cursory.

Williamson suggested that most doctors are not good at case finding because their professional expectations are rarely satisfied by the apparently mundane nature of the work..$^{16}$ Moreover, they may not recognise the extent to which their latent fears about growing old and boredom with repetitious complaints impair their therapeutic attitudes and behaviour. ${ }^{17}$

Most doctors consider opportunistic assessment to $\vec{N}$ be the most appropriate form of proactive care. ${ }^{18}$ At least three quarters of elderly patients see their general practitioner once a year or more, and assessments were probably carried out during those consultations.

The way in which nurses' work is organised gives them little occasion for opportunistic assessments. Invitations are therefore issued in a more formal way and this possibly explains the lower uptake (57\%). The wording of the invitation and the style in which it is offered may also affect the number of acceptances. Examination of practice invitations suggests no correlation between encouraging letters and high uptake, but there seems to be a connection between negative invitations and low uptake. This should be investigated further.

\section{TRAINED ASSESSORS}

Although health visitors seem the most appropriately trained to undertake case finding, most are reluctant to relinquish their traditional work with preschool children and their families. ${ }^{190}$ Over the past decade support has increased for qualified specialist nurses for elderly people. ${ }^{21} 22$ Wells and Freer suggested that with additional training in diagnostic skills and $\mathrm{O}$ prescribing specialist nurses would fulfil an important $N$ role in the primary health care team. ${ }^{23} \mathrm{My}$ results showed clear differences between practice nurses with and without specialist qualifications.

Wallace argued that there are insufficient staff in primary health care teams to carry out assessments adequately. He proposes employing trained link workers from various professional backgrounds to specialise in this work. Though he considers the demands of the $\mathscr{D}$ contract and the importance of data collection, Wallace does not mention health education, a key element in anticipatory care.

\section{SUMMARY}

This study represents an overview of the elderly assessment scheme in its first year, from which inevit- 8 ably new questions have emerged. Care of elderly people is a multidisciplinary exercise. With such disparity of views emanating from general practition- ? ers and practice nurses a means of providing a consistent service needs to be explored. Educational 
needs of doctors and nurses should be addressed and the development of specialist community nurses for elderly people further investigated.

This paper is based on a dissertation as part of an MSc in gerontology at the Age Concern Institute of Gerontology, King's College London. The support of my supervisor, Dr Emily Grundy, is gratefully acknowledged.

1 Williamson J, Stokoe IH, Gray S, Fisher M, Smith S, McGhee A, et al. Old people at home; their unreported needs. Lancet 1964;i:1117-20.

Taylor RC, Buckley EG, eds. Preventive care of the elderly: a review of curren Taylor RC, Buckley EG, eds. Preventive care of the elderly: a review of curren
developments. London: Royal College of General Practitioners, 1987, developments. London:

3 Grundy E. The epidemiology of ageing. In: Brocklehurst JC, Tallis R, Fillit H, eds. Textbook of geriatric medicine and gerontology. 4th ed. Edinburgh: Churchill Livingstone, 1992:1-20.

4 Office of Population Censuses and Surveys. General household survey 1985 London: HMSO, 1987.

Williams ES, Barley NH. Old people not known to the general practitioner: low risk group. $B M 7$ 1985;291:251-3.

6 Ebrahim S, Hedley R, Sheldon M. Low levels of ill health among elderly nonconsulters in general practice. BMF 1984;289:1273-5.

7 Vetter NJ, Jones DA, Victor CR. Effects of health visitors working with elderly patients in general practice: a randomised controlled trial. $B M \mathcal{J}$ 1984;288:369-72.

8 Barber $\mathrm{JH}$, Wallis JB, Mckeating E. A postal questionnaire in preventive care. fR Coll Gen Pract 1980;30:49-51.

9 Hendriksen C, Lund E, Stromgard E. Consequences of assessment and intervention among elderly people: a three year randomised controlled trial. BMF 1984:289:1522-4.
10 Illiffe S. Assessment of elderly people in general practice. 2. Functional abilities and medical problems. $\mathrm{Br} \mathcal{F}$ Gen Pract 1991;41:13-5.

11 Tulloch AJ, Moore V. A randomised controlled trial of geriatric screening surveillance in general practice. $\mathcal{F} R$ Coll Gen Pract 1979;29:733-42.

12 McEwan RT, Davison N, Forster DP, Pearson P, Stirling E. Screening elderly people in primary care: a randomized controlled trial. $\mathrm{Br} f$ Gen Pruct 1990;40:94-7.

13 Illiffe S, Haines A, Gallivan S, Booroff A, Goldenberg E, Morgan P. Assessment of elderly people in general practice 1 . Social circumstances and mental state. Br f Gen Pract 1991:41:9-12.

14 Wallace P. Linking up with the over 75s. Br f Gen Pract 1990;4:267-9.

15 Taylor R, Ford G, Barber H. The elderly al risk; a critical review of problems progress in screening and case finding. London: Age Concern Research Unit, 1983. (Research prospectives on ageing No 6 .)

16 Williamson J. Prevention, screening and case finding: an overview in care of the elderly. In: Taylor RC, Buckley EG, eds. Preventive care of the elderly: a review of current developments. London. Royal College of General Practitioners, 1987. (Occasional paper 35.)

17 Haug MR. Doctor-patient relationships and their impact on elderly self-care. In: Dean K, Hickey T, Holstein B, eds. Self-care and health in old age London: Croom Helm, 1986:230-47.

18 Freer CB. Consultation-based screening of the elderly in practice: a pilot study. F R Coll Gen Pract 1987;37:455-6.

19 Luker KA. Health visiting and the elderly. Health Visitor and Community Nurse 1979:15:457-9.

20 Tremellen RJ, Jones D. Attitudes of primary health care team towards elderly assessments. F R Coll Gen Pract 1989:39:142-4.

21 Redfern S. Nursing elderly people. Edinburgh: Churchill Livingstone, 1986.

22 Batchelor I. Policies for a crisis? Some aspecis of DHSS polices for the cure of the paper No 1.)

23 Wells $\mathrm{N}$, Freer $\mathrm{C}$. The ageing population: burden or challenge? London: Macmillan Press, 1988

(Accepted 30 fuly 1992)

\section{Partners in Practice}

\section{The developing primary care partnership}

\section{Mike Pringle}

This is the last of a series of articles focusing on the current tasks and functions of the primary health care team
Department of General

Practice, University of

Nottingham, Nottingham NG7 2UH

Mike Pringle, senior lecturer

$B M \mathcal{F}$ 1992;305:624-6
This series of articles has looked at a number of key issues in teamwork in primary care. It is clear that if a clean start could be made, primary health care teams would probably look substantially different from the ones we encounter today. The historical development of primary care has resulted from three concurrent pressures - political, organisational, and clinical.

\section{Development of primary care}

The existence of primary care teams can be largely attributed to the 1966 charter, which also limited the range of skills available within the team. The rules for reimbursing 70 per cent of staff costs defined eligible job descriptions; if that list had included physiotherapists, social workers, or counsellors the nature of primary care itself over the past 25 years would have been radically altered. The recent relaxations have given practices much more discretion but have also introduced the possibility of a lower reimbursement.

The second pressure has been organisational. The moves towards group practices, practice reports, audit, and computerisation have all emphasised the need for administration and management. The increasing sophistication of practice information systems for managing both clinical care and the resources of the practice has reached its apotheosis in fundholding. Practices joining this scheme require a level of internal organisation that would have seemed unachievable and unbelievable a decade ago.

Perversely the increasing management role in primary care has resulted in less involvement in management by some doctors. The arrival of practice managers with high level skills has freed general practitioners from administration and often from direct management responsibility. The increase in clerical staff has given the practitioners support with

\section{Key points}

- The primary health care team as we know it has developed largely in response to political, organisational, and clinical pressures

- Education is required for team members deficient in necessary skills

- The personal responsibility of each member within the team framework must be identified and accepted

- Patients should encounter the teams, not unconnected coworkers

- Every member of the practice should participate in quality assurance

- The result of effective teamwork should be, primarily, an increased quality of care

paperwork that their colleagues of 1966 could only envy.

The third major pressure derives from clinical evolution. In recent years there has been an accelerating transition of medical care into general practice. Child immunisation, developmental assessment, and family planning have been shared with agencies in district health authorities, but the 1990 contract has often led to their transfer to primary health care teams. The national surveillance of the "healthy" population through well person clinics, visits to the over $75 \mathrm{~s}$, and new services such as foreign travel clinics has augmented the workload and responsibility of primary care.

Through the 1980s there has been a shift in the care of patients with chronic disease from secondary care into general practice. The closure of many psychiatric 